\title{
Milk yield relative to supplement intake and rumination time differs by health status for fresh cows milked with automated systems
}

\author{
M. T. M. King, ${ }^{*}$ K. J. Sparkman, ${ }^{*}$ S. J. LeBlanc, $†$ and T. J. DeVries ${ }^{* 1}$ \\ *Department of Animal Biosciences, and \\ †Department of Population Medicine, University of Guelph, Guelph, Ontario, N1G 2W1, Canada
}

\begin{abstract}
Automated milking systems (AMS) provide the capability of adjusting the amount of supplemental concentrate offered to cows based on parity, days in milk, and milk yield; in many situations, more supplement is provided to those cows with higher production demands. To determine associations of subclinical ketosis (SCK) and blood $\beta$-hydroxybutyrate (BHB) with milk yield, supplement consumed in the AMS, rumination time, and the ratios of milk yield to supplement intake and milk yield to rumination time, we monitored 605 cows from 9 AMS herds, testing blood BHB concentrations $1 \times /$ wk for the first 3 wk of lactation. Milk yield, supplement intake, and rumination data were collected from the AMS computer on each farm. For analyses, only multiparous cows from 8 herds were included $(\mathrm{n}=$ 172 total) and were matched, within farm, to include an equal number of cows in each of 4 health status groups $(\mathrm{n}=43$ per group): $\mathrm{SCK}$ (BHB $\geq 1.2 \mathrm{mmol} / \mathrm{L}$ at $\geq 1$ of 3 tests, with no other disorder in the first $30 \mathrm{~d}$ in milk), SCK $+(\mathrm{BHB} \geq 1.2 \mathrm{mmol} / \mathrm{L}$ at $\geq 1$ of 3 tests, with another health disorder), HLT (BHB always $<1.2$ $\mathrm{mmol} / \mathrm{L}$, with no other disorder), or OTH (BHB always $<1.2 \mathrm{mmol} / \mathrm{L}$, with a health disorder). Milk yield and rumination time varied by health status, but we found no difference in supplement intake by health status group. As a result, milk yield relative to supplement intake and milk yield relative to rumination time differed by health status and were both positively associated with BHB. Cows in SCK had the highest milk yield and ratio of milk yield to supplement intake, but SCK+ cows had the lowest rumination time and the highest milk yield to rumination ratio. These results highlight the differences in milk production (per day and relative to supplement consumption or rumination time) associated with blood BHB and health status. Therefore,
\end{abstract}

Received February 28, 2018.

Accepted June 29, 2018.

${ }^{1}$ Corresponding author: tdevries@uoguelph.ca potential exists to modify supplementation in AMS to reduce negative energy balance by accounting for milk production of fresh cows.

Key words: robotic milking, energy balance, subclinical ketosis, management

\section{INTRODUCTION}

Automated (robotic) milking systems (AMS) and their associated management software are becoming increasingly useful tools for monitoring and managing dairy cow health. In terms of health monitoring, automatic sensors record a wealth of potentially valuable information, such as data regarding udder health, milk production, rumination time, and supplement intake in the AMS (Jacobs and Siegford, 2012). Regarding health management, AMS provide the capability of offering different types and amounts of supplemental feed to cows based on their parity, DIM, and milk yield. These options can be used to meet nutrient requirements for production and to possibly manage metabolic health of cows at the individual level. However, field observations indicate that settings used to adjust supplement allowance often do not take milk yield into account until wk 3 or 4 of lactation, and in some situations up to 70 DIM, all past the peak risk period for developing metabolic disorders.

Cows are particularly susceptible to health disorders during the first $3 \mathrm{wk}$ of lactation. Many cows in early lactation are affected by subclinical ketosis (SCK), which arises from maladaptation to negative energy balance (NEB; Herdt, 2000). A certain degree of NEB is expected in early-lactation cows, but SCK and other disorders can arise if cows excessively mobilize body stores to attempt to meet energy requirements for milk production, resulting in increased concentrations of BHB in the blood (Herdt, 2000) associated with increased disease risk. In recent research, AMS herds were reported to have a higher prevalence of SCK, based on milk BHB, than those milked by conventional systems (Tatone et al., 2017). Automated milking allows for more frequent milking than conventional systems, often 
resulting in increased milk yield (Wagner-Storch and Palmer, 2003; Bogucki et al., 2014; Sitkowska et al., 2015; De Marchi et al., 2017); this could increase the severity of NEB and risk of SCK, as a previous survey found AMS herds to have greater prevalence of high milk BHB, but also could have been due to differences in milking frequency or feed management (Tatone et al., 2017). Cows that experience SCK in early lactation are known to have reduced rumination time before and after calving compared with healthy cows (Kaufman et al., 2016).

Because cows have an intrinsically low motivation to be milked (Prescott et al., 1998), a highly palatable supplement is offered in the AMS to encourage cows to visit for milking. Various types of supplement can be offered, including, but not limited to, concentrate, glycol pellets, liquid glycol, high-moisture corn, dry corn, roasted soybeans, transition cow pellets, and liquid molasses (Keunen, 2015). Madsen et al. (2010) found that altering the composition and palatability of AMS concentrates affected milk production and the frequency of milk visits. Alternatively, Bach et al. (2007) studied the role of the amount of concentrate offered at the AMS and reported no effects on milking frequency, milk and component yields, or the need to fetch cows for milking. Researchers have not yet quantified associations of supplement consumption levels and rumination time with milk production and NEB of dairy cows in early lactation. The amount of supplement consumed at the AMS may influence energy balance and disease risk in early-lactation cows, because cows fed higherenergy diets during the first 3 wk after calving have been shown to have improved energy balance and more rapid production inclines in early lactation (Rabelo et al., 2005; Aghaziarati et al., 2011). Therefore, the aim of our study was to examine associations of milk yield (per day and relative to supplement consumed), AMS supplement intake, and rumination time with blood BHB and SCK status of dairy cows in early lactation. We hypothesized that higher BHB and SCK would be associated with lower rumination time and higher milk production, but also with lower supplement consumption.

\section{MATERIALS AND METHODS}

\section{Farms, Animals, and Housing}

This study was approved by the University of Guelph Research Ethics Board (REB \#14AP015) and the University of Guelph Animal Care Committee (AUP\#3140). The farms and cows were those used in a related observational study, where selection criteria and herd descriptions are reported and no experimental treatments were applied (King et al., 2018). In brief, producers milked $93 \pm 43$ (mean $\pm \mathrm{SD}$ ) cows with a median of 2 AMS units $(\mathrm{n}=4$ farms with 1 unit, $\mathrm{n}=2$ farms with 2 units, $\mathrm{n}=3$ farms with 3 or 4 units); thus, average stocking density was $53 \pm 9$ cows per AMS unit. All 9 farms used free-flow cow traffic and fresh cows were housed in bedded packs $(\mathrm{n}=1$ farm $)$, freestalls ( $\mathrm{n}=4$ farms), or both ( $\mathrm{n}=4$ farms), depending on the farm, as well as each cow's DIM and health status. Information on the nutrient content of partial mixed rations (PMR) and type of supplement provided in the AMS at each farm are described in Table 1. Farms were visited once per week, on the same day each week, across the entire study period. In total, 605 fresh cows from 9 herds were enrolled over a period of 6 mo (June 10 to December 13, 2016). Cows were enrolled upon freshening (0-7 DIM) and were followed for the first 3 wk of their lactation. In total, we monitored 212 primiparous and 393 multiparous cows. Multiparous cows were in their $3.2 \pm 1.4$ lactation (mean $\pm \mathrm{SD}$ ), ranging from 2 nd to 11 th parity.

\section{Data Collection}

All cows were milked by a Lely Astronaut (Lely Industries N.V., Maassluis, the Netherlands). Data were automatically collected by the AMS for each cow daily and were retrieved once per week from the AMS computer system at each farm. Data collected by the AMS for each cow included parity, DIM, calving date, and, for every visit to the AMS, the date and time, visit outcome (refusal, failure, or successful milking), and the amount of supplement consumed during successful and failed milkings. Respectively, successful and failed milkings were defined as those at which teat cup attachment was successful or not and whether the amount of milk collected either exceeded or did not meet the system's requirement to qualify as a milking event (i.e., successful teat attachment and at least $80 \%$ of a cow's expected yield for that milking). For both successful and failed milkings, AMS recorded information on total milk yield and supplement offered in the milking unit. Daily milk yield and AMS supplement intake were calculated as the sum of all milk collected and supplement consumed, respectively, regardless of whether it was from a successful or failed milking. Daily milking frequency was calculated as the sum of all successful milkings.

Rumination time was collected by electronic rumination-detection loggers on the neck collar of each cow in 2-h intervals (Lely Qwes-HR collars, Lely Industries N.V.). The collection of rumination data using these 
collars has been validated by Schirmann et al. (2009). These data were summarized by day for each cow from 1 to 21 DIM.

We assessed SCK by testing whole blood BHB concentrations of all enrolled cows once per week for the first 3 wk of lactation. Cows were tested during wk 1 $(4.0 \pm 2.0$ DIM, mean $\pm \mathrm{SD}), 2,(11.0 \pm 2.0 \mathrm{DIM})$, and $3(18.0 \pm 2.1 \mathrm{DIM})$ postpartum. Blood samples were taken within 2 to $4 \mathrm{~h}$ after fresh feed delivery on every farm, to capture peak daily BHB (Nikkhah et al., 2008). Blood samples from the coccygeal vein were tested immediately after collection using an electronic hand-held device (Freestyle Neo meter, Abbott Diabetes Care, Mississauga, Canada; validated by Kanz et al., 2015). In total, 525 cows had all 3 BHB tests and only those cows were considered for further analyses. Cows with $\mathrm{BHB} \geq 1.2 \mathrm{mmol} / \mathrm{L}$ at 1 or more of the 3 postpartum samples were classified as having SCK (McArt et al., 2012). Cows always having BHB <1.2 $\mathrm{mmol} / \mathrm{L}$ were classified as being healthy.

Monitoring and scoring methods for other health disorders were conducted as described in King et al. (2018) to assess every cow for lameness, displaced abomasum, retained placenta, metritis, milk fever, mastitis, and pneumonia. Four health status groups were created to categorize cows. We grouped cows with lameness in wk 1 or 3 of lactation or with any other health disorder in the first 30 DIM (OTH) and those who met the same criteria with SCK $(\mathbf{S C K}+)$ together. We also grouped cows with SCK and no other health disorder (SCK) together; those not diagnosed with any health disorder in the first 30 DIM were classified as healthy (HLT).

\section{Statistical Analyses}

Cows were matched across health categories, within farm, by parity and calving season. Because only 53 primiparous cows had health disorders (22 OTH, 18 SCK, $13 \mathrm{SCK}+$ ), and therefore too few cases for meaningful analyses, we excluded primiparous individuals from further analyses. All data from 1 herd $(\mathrm{n}=22$ cows) were removed from the analyses because of zero cases of SCK. We included an equal number of multiparous cows in each of the 4 health status groups when matching cows. Those with no match were excluded and only those with 3 BHB blood tests were included $(\mathrm{n}=172$ total). This resulted in 4 groups of 43 cows. With this sample size, based on a power analysis (Morris, 1999), we were able to detect (at $80 \%$ power) a minimum difference of $17.1 \%$ in milk yield, $14.4 \%$ in rumination time, $20.5 \%$ in milk yield-to-supplement intake, and $20.3 \%$ in milk yield-to-rumination time between health status categories.

Daily cow-level data were organized such that they were aligned with corresponding BHB results as well as each cow's health status. Prior to analyses, all data were screened for normality and outliers using the UNIVARIATE procedure of SAS (SAS Institute, 2013). For all analyses, outcomes were considered significant at $P$ $\leq 0.05$ and tendencies at $0.05<P \leq 0.10$.

Multivariable mixed effect linear regression models (using the MIXED procedure of SAS; SAS Institute, 2013) were used to test the effect of health status (HLT, OTH, SCK, SCK+) as a fixed effect in separate models of milk yield, milking frequency, supplement intake,

Table 1. Summary of the nutrient content for formulated lactating cow partial mixed rations and supplemental feeds provided in automated milking systems (AMS) on each study farm ${ }^{1}$

\begin{tabular}{|c|c|c|c|c|c|c|c|}
\hline Herd & \multicolumn{5}{|c|}{ Partial mixed ration nutrient content } & $\begin{array}{l}\text { AMS supplement } \\
\text { type }(\mathrm{s})^{2}\end{array}$ & $\begin{array}{l}\text { Mean supplement } \\
\text { intake }^{3}(\mathrm{~kg} / \mathrm{d} \text { as fed })\end{array}$ \\
\hline 2 & 41.7 & 40.8 & 27.1 & 16.3 & 1.52 & Robot pellet & 3.4 \\
\hline 3 & 46.1 & 34.9 & 20.9 & 15.7 & 1.66 & Robot pellet, palm fat & 3.9 \\
\hline 5 & 44.0 & 36.7 & 21.8 & 15.6 & 1.59 & $\begin{array}{l}\text { Robot pellet, fresh cow pellet, } \\
\text { corn and roasted soybeans }\end{array}$ & 3.6 \\
\hline 6 & 42.5 & 37.7 & 23.4 & 15.9 & 1.63 & Robot pellet & 4.3 \\
\hline 7 & 44.9 & 33.2 & 19.4 & 15.3 & 1.63 & Robot pellet & 4.3 \\
\hline 8 & 39.4 & 34.2 & 21.5 & 16 & 1.51 & Robot pellet & 4.7 \\
\hline
\end{tabular}

${ }^{1}$ Information was collected for 8 study farms (1 farm was excluded due to zero cases of subclinical ketosis).

${ }^{2}$ Seven farms fed a standard robot pellet with 18 to $19 \%$ CP (range 17-23\% CP, 88-90\% DM). Molasses (farms 1 and 4 ) had $64.7 \%$ DM and $10.6 \%$ CP. Palm fat (farm 3) had 98\% DM and 0\% CP. Fresh cow pellet (farm 5) had 90\% DM and 10.5\% CP. Nutrient specifications were unavailable for farm 1 and 4 corn/soybean mixes.

${ }^{3}$ For all multiparous cows on each study farm (not just matched individuals) from 1 to 21 DIM. 
rumination time, milk yield-to-supplement intake, and milk yield-to-rumination time. We included DIM as a fixed effect in models as well as the interaction between DIM and health status. The random effect was farm. We included repeated measures (DIM), with compound symmetry as the covariance structure for all models, on the basis of best fit according to the lowest Bayesian information criterion values, with cow within farm as the subject of the repeated measure.

Milk yield, supplement intake, rumination time, milk yield-to-supplement intake, and milk yield-to-rumination time were also associated with BHB concentrations using linear regressions (REG procedure in SAS; SAS Institute, 2013). To account for day-to-day variability, 3 -d centered means for each variable were used, and data before 1 DIM were excluded due to some cows not having data from 0 DIM. Models were used to test 3-d means for each independent variable as a fixed effect against the respective BHB value. Logistic regression models (using the GLIMMIX procedure of SAS with a binomial distribution and logit link; SAS Institute, 2013) were used to identify factors associated with BHB $\geq 1.2 \mathrm{mmol} / \mathrm{L}$, considering each predictor separately. Degrees of freedom for fixed effects were estimated using the Kenward-Roger option in the MODEL statement. Random effects were farm and cow within farm.

\section{RESULTS}

Various farm-level differences were present in our study, such as management, feeding program, and housing (described in King et al., 2018). Although each farm provided a slightly different amount, number, or type of supplemental feed in the AMS (Table 1), AMS at all farms were programmed to feed based only on DIM and not by production level; cows were offered between 2 and $3 \mathrm{~kg} / \mathrm{d}$ for the first 5 DIM, with 6 of the 8 farms having 1 step-up between 5 and 14 DIM, 1 farm with 2 step-ups (at 7 and 14 DIM), and 1 farm continuously allotting the same amount for the first $3 \mathrm{wk}$ of lactation. Overall, supplement consumption was similar between farms and there were minimal differences in energy density and nutrient breakdown of the PMR between farms (Table 1). To account for differences between farms, multiparous cows were matched within farm to balance differences in nutritional programs and general management across farms.

Milk yield of multiparous cows varied by health status $(P<0.001)$, such that cows in SCK produced the most milk and OTH cows were the least productive (Figure 1a). We also observed different milking frequencies for each group $(P=0.003)$, such that HLT cows milked most frequently, followed by SCK and OTH, and SCK + cows milked the least often (Figure 1b).
Despite these differences in production, we found no difference in supplement intake by health status group $(P=0.11$; Figure 1a); therefore, there were differences in milk yield-to-supplement intake by health status $(P$ $<0.001$; Figure 1d). With no difference in supplement intake between groups, SCK cows, therefore, had the highest ratio of milk production to supplement intake (Figure 1b). Cows that were either HLT or SCK+ had an intermediate milk yield-to-supplement intake ratio, and OTH cows had the lowest milk yield-to-supplement intake ratio (Figure 1d). Despite their intermediate milk yield and milk yield-to-supplement intake, SCK+ cows had the lowest rumination times $(P<0.001$; Figure 1c). Therefore, SCK + cows had the highest ratio of milk yield-to-rumination, particularly in the first week of lactation, and OTH cows had the lowest ratios $(P$ $<0.001$; Figure 1e). Additionally, SCK + cows exhibited steep increases in milk-to-supplement and milkto-rumination in the first few DIM, followed by sharp reductions, whereas SCK cows had a reduction from an initially high milk yield-to-rumination time from 1 to 3 DIM and their initial milk yield-to-supplement intake increased rapidly but was then stable (Figure 1d,e).

Although milk yield and supplement intake were not associated with BHB in linear regressions $(P>0.2)$ or SCK in logistic regressions (Table 2) from 1 to 21 DIM, milk yield-to-supplement intake was positively associated with BHB. For each 1-unit increase in milkto-supplement, BHB increased by $0.05 \mathrm{mmol} / \mathrm{L}(P$ $=0.002)$ and the odds of having $\mathrm{BHB} \geq 1.2 \mathrm{mmol} / \mathrm{L}$ increased by $1.1 \times$ (Table 2 ). In contrast, rumination time was negatively associated $(P<0.001)$ with BHB, such that each reduction of $60 \mathrm{~min} / \mathrm{d}$ in rumination time was associated with a $0.09 \mathrm{mmol} / \mathrm{L}$ increase in blood BHB. Milk yield-to-rumination time was, thus, also associated with BHB, whereby an increase of $4 \mathrm{~kg}$ of milk from the mean of $36.3 \mathrm{~kg} / \mathrm{d}$ (i.e., to $40.3 \mathrm{~kg} / \mathrm{d}$ ) with a rumination time of $400 \mathrm{~min} / \mathrm{d}$ was associated with an increase of $0.07 \mathrm{mmol} / \mathrm{L}$ in BHB $(P<0.001)$ and the odds of having $\mathrm{BHB} \geq 1.2 \mathrm{mmol} / \mathrm{L}$ increased by 1.2 fold (Table 2 ).

\section{DISCUSSION}

The results from both types of analyses (linear/ logistic regressions and comparisons by health status group) support the importance of promoting adequate energy consumption and rumination behavior during early lactation to maintain metabolic health. Higher BHB concentrations were associated with greater milk production for multiparous cows, and SCK cows produced the most milk. Cows producing less milk were likely more capable of meeting their energy demands, whereas higher-producing cows were likely not meeting 

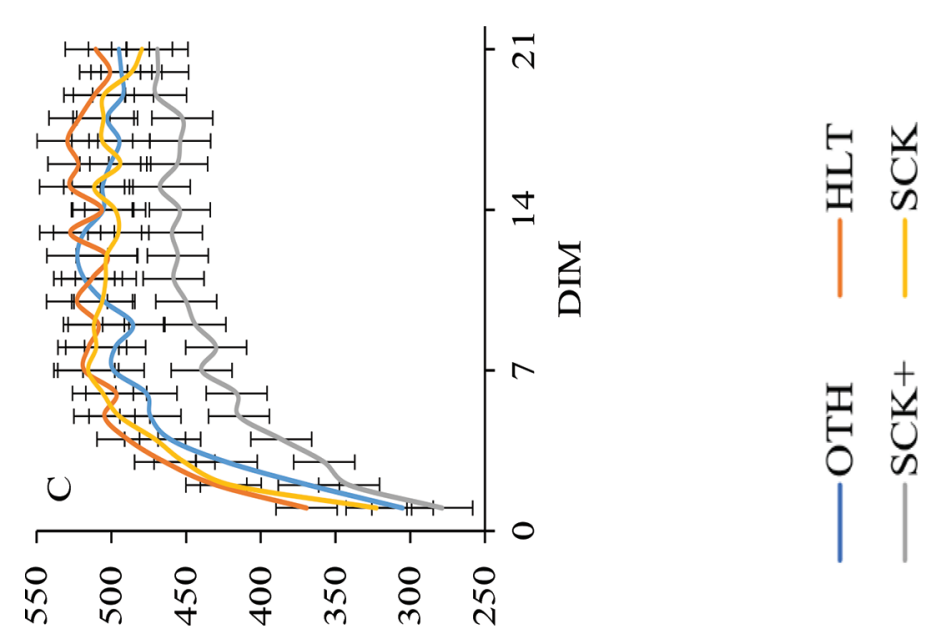

(p/u!u) วщ!̣ uo!ฺ̣uाuny
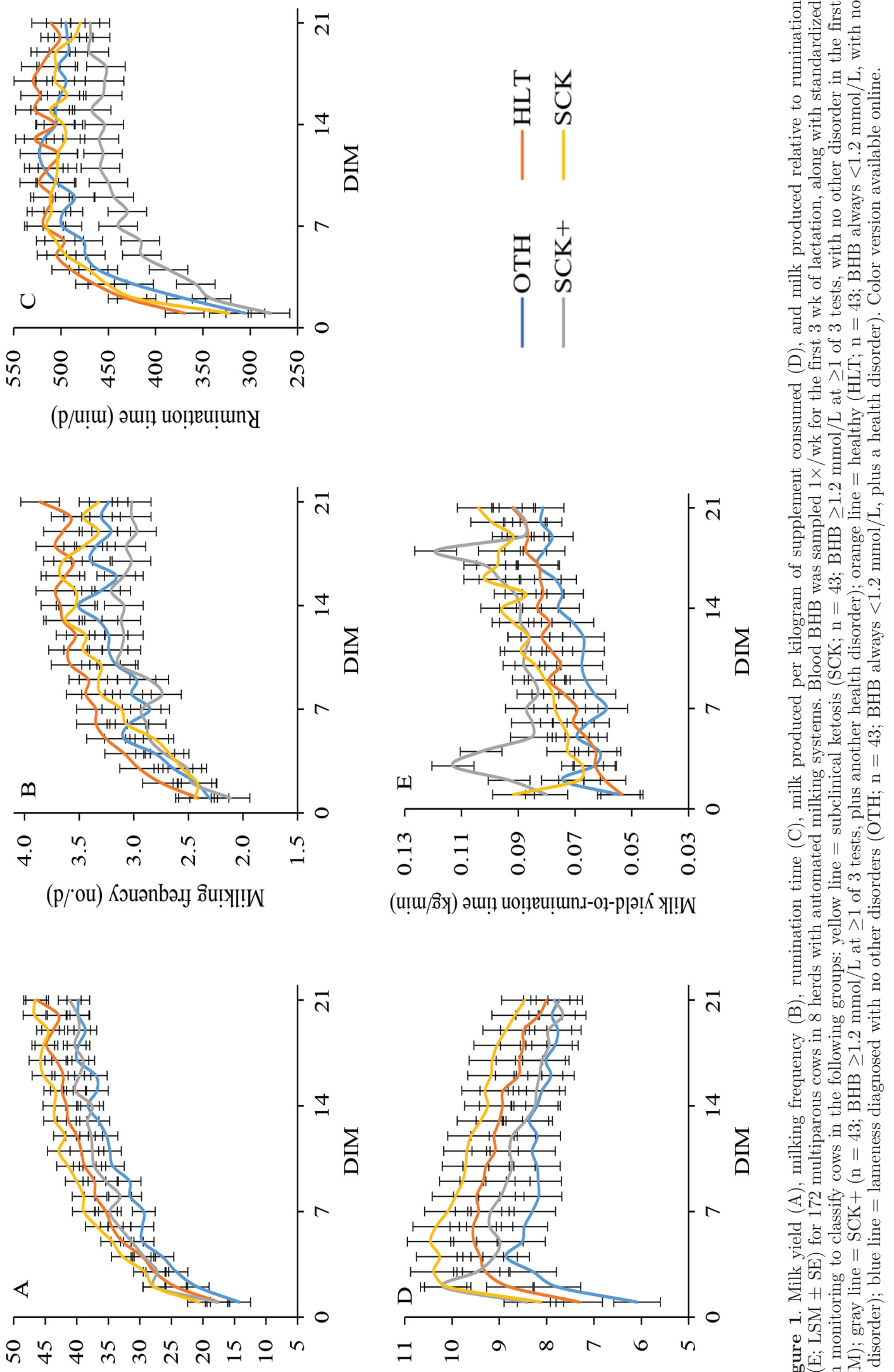

(p/ôy) p|ə!К צІ!!W

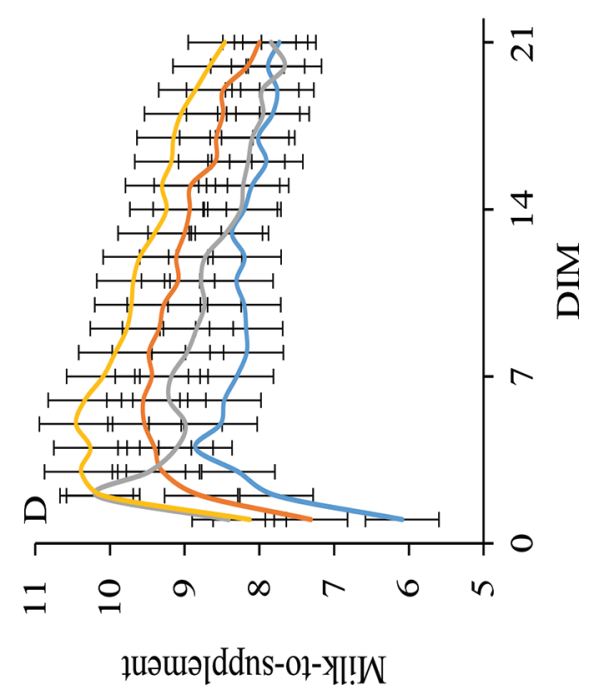

คิธ

$\rightarrow . \exists \sim$

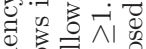

छ유

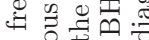

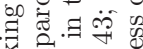

$\exists=$

$\exists$ 키 0 व

至密要

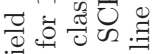

不同용

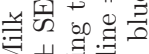

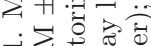

该. 者

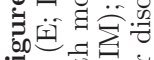

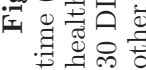


their energy needs and, therefore, had higher blood BHB and greater risk of SCK. Thus, our data support the concept that greater milk production is associated with SCK (Vanholder et al., 2015), as cows with SCK and no other health disorder were the highest-producing group in our study. However, cows with SCK and another disorder had reduced milk production, which was also recently demonstrated by Kaufman et al. (2018) for second-lactation cows. The difference between SCK+ and SCK cows may explain why Goldhawk et al. (2009) saw no difference between milk yield or daily change in milk yield between SCK and healthy cows. Looking within cows with SCK, however, Gáspárdy et al. (2014) reported a negative deviation in milk yield and rumination time with onset of SCK, as did King et al. (2017b). Finally, cows with clinical ketosis have been previously shown to have deviations in milk yield from themselves and from healthy herd mates (Steensels et al., 2017; Paudyal et al., 2018).

Milking frequency differences observed between groups were somewhat similar to milk yield results, but cows who were completely healthy in our study had the highest frequency of milkings per day, followed by those with SCK only. It appears that having a disorder besides SCK particularly affected milking frequency, because OTH and SCK + cows had the lowest milking frequencies. It is plausible that other health disorders, such as mastitis or lameness, reduced the mobility and motivation for cows to visit the AMS to be milked, as previous studies have reported reduced milk frequency with lameness and hoof disorders (King et al., 2017a,b),

Table 2. Summary of logistic regression models of associations of milk yield, supplement intake, and rumination time with cases of subclinical ketosis (BHB $\geq 1.2 \mathrm{mmol} / \mathrm{L}$ ) from 1 to $22 \mathrm{DIM}$ ( $\mathrm{n}=516$ blood samples from 172 multiparous cows in 8 herds with automated milking systems $)^{1}$

\begin{tabular}{lccc}
\hline & \multicolumn{2}{c}{ Odds ratio } & \\
\cline { 2 - 3 } Variable & Estimate & $95 \% \mathrm{CI}$ & \\
\hline & & & \\
& -value \\
Milk yield $^{2}(\mathrm{~kg} / \mathrm{d})$ & 1.07 & $0.98-1.17$ & 0.11 \\
Supplement intake $^{3}(\mathrm{~kg} / \mathrm{d})$ & 1.04 & $0.85-1.27$ & 0.7 \\
Rumination time $^{4}(\mathrm{~min} / \mathrm{d})$ & 1.24 & $1.09-1.41$ & 0.001 \\
Milk yield:supplement intake $^{5}(\mathrm{~kg} / \mathrm{kg})$ & 1.12 & $1.01-1.23$ & 0.03 \\
Milk yield:rumination time $^{6}(\mathrm{~kg} / \mathrm{min})$ & 1.22 & $1.12-1.34$ & $<0.001$ \\
\hline
\end{tabular}

${ }^{1}$ Blood BHB was sampled $1 \times /$ wk for the first $3 \mathrm{wk}$ of lactation.

${ }^{2}$ For an increase of $4 \mathrm{~kg}$ from the mean $(36.3 \mathrm{~kg} / \mathrm{d})$ daily milk production.

${ }^{3}$ For an increase of $1 \mathrm{~kg}$ from the mean $(4.3 \mathrm{~kg} / \mathrm{d})$ supplement intake.

${ }^{4}$ For a decrease of $60 \mathrm{~min} / \mathrm{d}$ from the mean $(478 \mathrm{~min} / \mathrm{d})$ rumination time.

${ }^{5}$ For an increase of $1 \mathrm{~kg} / \mathrm{kg}$ from the mean (8.7) milk yield:supplement intake.

${ }^{6}$ For an increase of $0.01 \mathrm{~kg} / \mathrm{min}$ from the mean $(0.079 \mathrm{~kg} / \mathrm{min})$ milk yield:rumination time.
SCK, mastitis, displaced abomasum, and development of lameness (King et al., 2018).

Despite their greater production and associated energy demands, cows with higher BHB concentrations were not offered greater amounts of supplemental feed in the AMS, nor were there any differences in intake between health status groups. As a result, milk yield relative to the amount of AMS supplement consumed was associated with higher BHB concentrations and was greater for cows in SCK. We also observed an initial spike in milk yield-to-supplement intake at 2 DIM for $\mathrm{SCK}+$ cows; after this spike, corresponding to declining milk yield-to-supplement intake, the ratio of milk yield to rumination time spiked for SCK+ cows from 2 to 4 DIM. For this measure, it appears that SCK + cows experienced the largest discrepancy in milk yield-torumination time of the health status categories. The rapid and nonproportional change in milk yield relative to rumination time was not predicted but was not entirely surprising, as Kaufman et al. (2016) also reported reduced rumination time for cows with SCK, especially for those with other health disorders, both before and after calving by approximately 50 and $90 \mathrm{~min} / \mathrm{d}$, respectively, compared with healthy cows. Steensels et al. (2017) found that cows with ketosis had the lowest rumination times out of all health disorders they assessed. Schirmann et al. (2016) only observed reduced rumination time for SCK cows before calving (by 1 h/d), but SCK + and SCK cows had lower DMI before and after calving, and there were numerical differences in rumination time. Liboreiro et al. (2015) found no difference in rumination time between SCK and healthy cows precalving and only 2 of $16 \mathrm{~d}$ differed postcalving. The differences between SCK and SCK+ cows in the current study support the notion that additional health challenges further impair rumination behavior, as seen by Kaufman et al. (2016).

The reduced rumination behavior of SCK + cows may be indicative of reduced appetite and lower overall feed intake or, specifically, consumption of PMR. Unfortunately, it was not possible to collect individual PMR intake data for our study; thus, it was not possible to calculate energy consumption. Nonetheless, increasing AMS supplement allowance, by accounting for production of higher-producing fresh cows, has the potential to reduce the risk of SCK, provided that any increase in supplement provision be matched with an effort to maintain, or potentially increase, PMR intake. Bach et al. (2007) found that increasing concentrate allowance at the AMS (6.8 vs. $2.6 \mathrm{~kg} / \mathrm{d}$ ) resulted in a slight decrease in overall DMI because cows ate less PMR. This may put cows at a greater risk for rumen health problems, such as acidosis, as decreasing intake at the bunk would subsequently decrease intake of 
physically effective NDF (Owens et al., 1998). Recently, Hare et al. (2018) also found that cows compensate for increased AMS concentrate intake (5.0 vs. $0.5 \mathrm{~kg} / \mathrm{d}$ ) by reducing their PMR intake. However, the difference in AMS concentrate consumption between treatments in that study and in Bach et al. (2007) is much larger than would result from controlling for milk yield in supplement allowance settings from 7 to 10 DIM onwards. It is possible to start the milk curve (i.e., give increasing supplement with increasing milk yield) even earlier, but milk yield in the first week of lactation is often too variable on which to base supplement allowance. During the present study, conducted in 2016, from 0 to 30 DIM cows consumed, on average, $4.66 \mathrm{~kg} / \mathrm{d}$ of supplement, which is similar to industry estimates of supplement provision, across lactation, for other North American herds, averaging $4.76 \mathrm{~kg} / \mathrm{d}$ (using data from Tremblay et al., 2016). Based on observations made at farms included in our study, when feed tables began to account for milk production, cows were offered 2 to $10 \mathrm{~kg} / \mathrm{d}$ of supplement based on milk yield $<20$ to $65 \mathrm{~kg} / \mathrm{d}$. Therefore, instead of feeding a typical, basal amount of supplement from 7 to 10 DIM onwards, producers could use those same settings, but begin controlling for milk yield at that point onwards. From 7 to 10 DIM, when production averaged 29 to $41 \mathrm{~kg} / \mathrm{d}$ in our study, this would be equivalent to a potential increase of approximately 0.4 to $3.2 \mathrm{~kg} / \mathrm{d}$ supplement, based on how aggressive the milk curve is designed, whereas previous studies compared treatments that differed by 4.2 and $4.5 \mathrm{~kg} / \mathrm{d}$ (Bach et al., 2007; Hare et al., 2018). Similarly, from 14 to 21 DIM (average milk yield $36-46 \mathrm{~kg} / \mathrm{d}$ in the current study), this would be equivalent to a potential increase of approximately 2 $\mathrm{kg} / \mathrm{d}$ compared with what study farms were feeding at the time of our data collection. With these potential increases in supplement provision, it is key to remember that there is also the potential for a similar reduction in programmed supplement allowance if the cow is not producing high quantities of milk. Therefore, the change in supplement allowance accounting for milk production would not be as large a difference as those previous studies and we would not expect the same drop in PMR intake. However, if concentrate allowance is to be even slightly increased for high-producing cows, it is vital that they are still encouraged to feed at the bunk to maintain good intake of PMR and a healthy rumen environment. Currently the opportunity exists to adjust robot concentrate allocation at earlier DIM based on production, but more research is required to understand the outcome of starting milk curves earlier and to achieve the optimal balance between PMR and supplement intake. It may not be possible to balance concentrate and PMR intake in all situations, and in these cases other options to increase energy consumption should be explored.

Some researchers have found that early-lactation cows fed a higher concentrate diet lost less weight and body condition and had lower BHB values at 21 DIM compared with cows fed less concentrate (Andersen et al., 2003; Rabelo et al., 2005). Currently no published studies have evaluated precision feeding strategies to improve energy balance and milk yield of early-lactation AMS-milked cows, and related research provides conflicting evidence that increasing supplementation may reduce DMI and milk yield (Penner et al., 2017). Therefore, accounting for early-lactation milk production for AMS feeding requires further research. Other researchers have tested different rates of grain inclusion in fresh cow diets, demonstrating reduced fermentable OM intake for cows slowly adapted to higher grain inclusion compared with those adapted rapidly (Dieho et al., 2016). Therefore, Penner et al. (2017) suggested that feeding strategies designed to closely meet cows' energetic needs may, in fact, overwhelm their ability to consume those diets and may not improve their performance. With this knowledge, it may be more beneficial to offer a different type of energy supplement (such as glycerol or molasses) rather than greater quantity.

Finally, cows in the current study were consuming PMR that had moderately high $\mathrm{NE}_{\mathrm{L}}$. Had the PMR been lower in energy, we would have expected even greater differences between health status groups in terms of milk yield; on the other hand, rumination time may be greater if PMR is diluted with roughage. Lowenergy PMR also means there is a greater need and opportunity for supplementation for early-lactation cows with high production demands, which, again, needs to be balanced with PMR intake and overall feed intake. Therefore, modifying the settings for feed supplementation in AMS to account for milk yield needs to be done early in lactation to provide an appropriate energy boost for high-yielding cows. Whereas milk production may be too variable in the first week of lactation, feed tables could potentially be adjusted to start accounting for milk yield as early as 7 to 10 DIM to proportionately supplement high-producing cows and reduce their risk of developing SCK.

\section{CONCLUSIONS}

Milk production relative to supplement intake and rumination time were positively associated with blood BHB and differed by health status for cows milked in automated systems, but we found no such associations with supplement intake. In summary, SCK cows had the highest milk yield and ratio of milk yield to supplement intake, but SCK + cows had the lowest rumination time 
and the highest milk yield-to-rumination ratio. These results suggest that AMS settings need to account for milk production of cows during their first 3 wk of lactation when determining supplemental pellet allowance.

\section{ACKNOWLEDGMENTS}

We are especially grateful to the participating producers who allowed us access to their animals and AMS data. Robyn Walsh (Grand River Robotics, Ontario, Canada) kindly helped us recruit farms and provided technical support throughout the project. Thank you to those who helped collect data, including Emily Kaufman, Felipe Pádua, Isabela Salmazo, Michelle Thompson, and Sarah McPherson, all from the University of Guelph (Ontario, Canada). This project was financially supported by a contribution from the Dairy Research Cluster II Initiative, funded by the Dairy Farmers of Canada (Ottawa, ON, Canada), Agriculture and Agri-Food Canada (Ottawa, ON, Canada), the Canadian Dairy Network (Guelph, ON, Canada), and the Canadian Dairy Commission (Ottawa, ON, Canada), as well as in part by funding from the Canada First Research Excellence Fund (Ottawa, ON, Canada).

\section{REFERENCES}

Aghaziarati, N., H. Amanlou, D. Zahmatkesh, E. Mahjoubi, and M. H. Yazdi. 2011. Enriched dietary energy and protein with more frequent milking offers early lactation cows a greater productive potential. Livest. Sci. 136:108-113. https://doi.org/10.1016/j.livsci .2010 .08 .006 .

Andersen, J. B., N. C. Friggens, K. Sejrsen, M. T. Sørensen, L. Munksgaard, and K. L. Ingvartsen. 2003. The effects of low vs. high concentrate level in the diet on performance in cows milked two or three times daily in early lactation. Livest. Prod. Sci. 81:119-128. https://doi.org/10.1016/S0301-6226(02)00303-2.

Bach, A., C. Iglesias, S. Calsamiglia, and M. Devant. 2007. Effect of amount of concentrate offered in automatic milking systems on milking frequency, feeding behavior, and milk production of dairy cattle consuming high amounts of corn silage. J. Dairy Sci. 90:5049-5055. https://doi.org/10.3168/jds.2007-0347.

Bogucki, M., A. Sawa, and W. Neja. 2014. Effect of changing the cow milking system on daily yield and cytological quality of milk. Acta Sci. Pol. Zootech. 13:17-26.

De Marchi, M., M. Penasa, and M. Cassandro. 2017. Comparison between automatic and conventional milking systems for milk coagulation properties and fatty acid composition in commercial dairy herds. Ital. J. Anim. Sci. 16:363-370. https://doi.org/10.1080/ 1828051X.2017.1292412.

Dieho, K., A. Bannink, A. L. Guerts, J. T. Schonewille, G. Gort, and J. Dijkstra. 2016. Morphological adaptation of rumen papillae during the dry period and early lactation as affected by rate of increase of concentrate allowance. J. Dairy Sci. 99:2339-2352. https: //doi.org/10.3168/jds.2015-9837.

Gáspárdy, A., G. Efrat, A. C. Bajcsy, and S. G. Fekete. 2014. Electronic monitoring of rumination activity as an indicator of health status and production traits in high-yielding dairy cows. Acta Vet. Hung. 62:452-462. https://doi.org/10.1556/AVet.2014.026.

Goldhawk, C., N. Chapinal, D. M. Veira, D. M. Weary, and M. A. G. von Keyserlingk. 2009. Prepartum feeding behavior is an early indicator of subclinical ketosis. J. Dairy Sci. 92:4971-4977. https:/ /doi.org/10.3168/jds.2009-2242.

Hare, K., T. J. DeVries, K. S. Schwartkopf-Genswein, and G. B. Penner. 2018. Does the location of concentrate provision affect voluntary visits, and milk and milk component yield for cows in an automated milking system? Can. J. Anim. Sci. 98:399-404. https: //doi.org/10.1139/CJAS-2017-0123.

Herdt, T. H. 2000. Ruminant adaptation to negative energy balance. Vet. Clin. North Am. Food Anim. Pract. 16:215-230. https://doi .org/10.1016/S0749-0720(15)30102-X.

Jacobs, J. A., and J. M. Siegford. 2012. Invited review: The impact of automatic milking systems on dairy cow management, behavior, health, and welfare. J. Dairy Sci. 95:2227-2247. https://doi.org/ 10.3168/jds.2011-4943.

Kanz, P., M. Drillich, D. Klein-Jöbstl, B. Mair, S. Borchardt, L. Meyer, I. Schwendenwein, and M. Iwersen. 2015. Suitability of capillary blood obtained by a minimally invasive lancet technique to detect subclinical ketosis in dairy cows by using 3 different electronic hand-held devices. J. Dairy Sci. 98:6108-6118. https://doi .org/10.3168/jds.2014-8957.

Kaufman, E. I., S. J. LeBlanc, B. W. McBride, T. F. Duffield, and T. J. DeVries. 2016. Association of rumination time with subclinical ketosis in transition dairy cows. J. Dairy Sci. 99:5604-5618. https: //doi.org/10.3168/jds.2015-10509.

Kaufman, E. I., V. H. Asselstine, S. J. LeBlanc, T. F. Duffield, and T. J. DeVries. 2018. Association of rumination time and health status with milk yield and composition in early-lactation dairy cows. J. Dairy Sci. 101:462-471. https://doi.org/10.3168/jds.2017-12909.

Keunen, J. 2015. Options Abound with Feeds for Robotic Milking. Progressive Dairyman: Canada. Accessed Apr. 1, 2017. http:// www.progressivedairycanada.com/topics/feed-nutrition/options -abound-with-feeds-for-robotic-milking.

King, M. T. M., K. M. Dancy, S. J. LeBlanc, E. A. Pajor, and T. J. DeVries. 2017b. Deviations in behavior and productivity data before diagnosis of health disorders in cows milked with an automated system. J. Dairy Sci. 100:8358-8371. https://doi.org/10 $.3168 /$ jds.2017-12723.

King, M. T. M., S. J. LeBlanc, E. A. Pajor, and T. J. Devries. 2017a. Cow-level associations of lameness, behavior, and milk yield of cows milked in automated systems. J. Dairy Sci. 100:4818-4828. https://doi.org/10.3168/jds.2016-12281.

King, M. T. M., S. J. LeBlanc, E. A. Pajor, T. C. Wright, and T. J. DeVries. 2018. Behavior and productivity of cows milked in automated systems prior to diagnosis of health disorders in early lactation. J. Dairy Sci. 101:4343-4356. https://doi.org/10.3168/ jds.2017-13686.

Liboreiro, D. N., K. S. Machado, P. R. B. Silva, M. M. Maturana, T. K. Nishimura, A. P. Brandão, M. I. Endres, and R. C. Chebel. 2015. Characterization of peripartum rumination and activity of cows diagnosed with metabolic and uterine diseases. J. Dairy Sci. 98:6812-6827. https://doi.org/10.3168/jds.2014-8947.

Madsen, J., M. R. Weisbjerg, and T. Hvelplund. 2010. Concentrate composition for automatic milking systems-Effect on milking frequency. Livest. Sci. 127:45-50. https://doi.org/10.1016/j.livsci 2009.08.005.

McArt, J. A. A., D. V. Nydam, and G. R. Oetzel. 2012. Epidemiology of subclinical ketosis in early lactation dairy cattle. J. Dairy Sci. 95:5056-5066. https://doi.org/10.3168/jds.2012-5443.

Morris, T. R. 1999. Experimental Design and Analysis in Animal Sciences. CABI Publishing, New York, NY.

Nikkhah, A., C. J. Furedi, A. D. Kennedy, G. H. Crow, and J. C. Plaizier. 2008. Effects of feed delivery time on feed intake, milk production, and blood metabolites of dairy cows. J. Dairy Sci. 91:4249-4260. https://doi.org/10.3168/jds.2008-1075.

Owens, F. N., D. S. Secrist, W. J. Hill, and D. R. Gill. 1998. Acidosis in cattle: A review. J. Anim. Sci. 76:275-286. https://doi.org/10 $.2527 / 1998.761275 x$.

Paudyal, S., F. P. Maunsell, J. T. Richeson, C. A. Risco, D. A. Donovan, and P. J. Pinedo. 2018. Rumination time and monitoring of health disorders during early lactation. Animal 12:1484-1492. https://doi.org/10.1017/S1751731117002932. 
Penner, G., S. Menajovsky, and K. Paddick. 2017. Optimal feeding programs with automated milking systems (AMS). WCDS Adv. Dairy Technol. 29:339-354.

Prescott, N. B., T. T. Mottram, and A. J. F. Webster. 1998. Relative motivations of dairy cows to be milked or fed in a Y-maze and an automatic milking system. Appl. Anim. Behav. Sci. 57:23-33. https://doi.org/10.1016/S0168-1591(97)00112-3.

Rabelo, E., R. L. Rezende, S. J. Bertics, and R. R. Grummer. 2005. Effects of pre- and postfresh transition diets varying in dietary energy density on metabolic status of periparturient dairy cows. J. Dairy Sci. 88:4375-4383. https://doi.org/10.3168/jds.S0022 $-0302(05) 73124-6$.

SAS Institute. 2013. SAS version 9.4. SAS Institute Inc., Cary, NC.

Schirmann, K., M. A. G. von Keyserlingk, D. M. Weary, D. M. Veira, and W. Heuwieser. 2009. Technical note: Validation of a system for monitoring rumination in dairy cows. J. Dairy Sci. 92:6052-6055. https://doi.org/10.3168/jds.2009-2361.

Schirmann, K., D. M. Weary, W. Heuwieser, N. Chapinal, R. L. A Cerri, and M. A. G. von Keyserlingk. 2016. Short communication: Rumination and feeding behaviors differ between healthy and sick dairy cows during the transition period. J. Dairy Sci. 99:99179924. https://doi.org/10.3168/jds.2015-10548.

Sitkowska, B., D. Piwczynski, J. Aerts, and M. Waskowicz. 2015. Changes in milking parameters with robotic milking. Arch. Tierzucht 58:137-143. https://doi.org/10.5194/aab-58-137-2015.
Steensels, M., E. Maltz, C. Bahr, D. Berckmans, A. Antler, and I. Halachmi. 2017. Towards practical application of sensors for monitoring animal health: The effect of post-calving health problems on rumination duration, activity and milk yield. J. Dairy Res. 84:132-138. https://doi.org/10.1017/S0022029917000176.

Tatone, E. H., T. F. Duffield, S. J. LeBlanc, T. J. DeVries, and J. L. Gordon. 2017. Investigating the within-herd prevalence and risk factors for ketosis in dairy cattle in Ontario as diagnosed by the test-day concentration of $\beta$-hydroxybutyrate in milk. J. Dairy Sci. 100:1308-1318. https://doi.org/10.3168/jds.2016-11453.

Tremblay, M., J. P. Hess, B. M. Christenson, K. K. McIntyre, B. Smink, A. J. van der Kamp, L. G. de Jong, and D. Döpfer. 2016. Factors associated with increased milk production for automatic milking systems. J. Dairy Sci. 99:3824-3837. https://doi.org/10 $.3168 /$ jds.2015-10152.

Vanholder, T., J. Papen, R. Bemers, G. Vertenten, and A. C. B. Berge. 2015. Risk factors for subclinical and clinical ketosis and association with production parameters in dairy cows in the Netherlands. J. Dairy Sci. 98:880-888. https://doi.org/10.3168/jds.2014-8362.

Wagner-Storch, A. M., and R. W. Palmer. 2003. Feeding behavior, milking behavior, and milk yields of cows milked in a parlor versus an automatic milking system. J. Dairy Sci. 86:1494-1502. https:// doi.org/10.3168/jds.S0022-0302(03)73735-7. 